\title{
Management Challenges and Outcomes of Traumatic Brain Injury due to Bear Maul in Tribal Areas of Chhattisgarh, India-Man versus Wild
}

\author{
Praveen Borde ${ }^{1}$ Sanjeev Kumar ${ }^{1} \quad$ Debabrata Sahana ${ }^{1} \quad$ Lavlesh Rathore $^{1} \quad$ Amit Jain ${ }^{1}$ \\ Manish Tawari ${ }^{1}$ Rajiv Sahu ${ }^{1}$ \\ ${ }^{1}$ Department of Neurosurgery, DKS Postgraduate Institute and \\ Address for correspondence Sanjeev Kumar, MCh, Department \\ Research Center, Raipur, Chhattisgarh, India \\ of Neurosurgery, DKS Postgraduate Institute and Research Center, \\ Raipur, Chhattisgarh 492001, India \\ (e-mail: ksanjeev79@gmail.com).
}

J Neurosci Rural Pract 2021;12:504-511.

\begin{abstract}
Objectives Neurosurgeons working in the vicinity of tribal areas face traumatic brain injury (TBI) cases due to bear maul which is on the rise in Chhattisgarh. Most of the literature is focused on the management of maxillofacial injuries. This study intends to describe the challenges in management and outcomes of TBI due to bear maul.

Materials and Methods A retrospective review was conducted from May 2018 to April 2020. The patients without TBI were excluded. The variables studied were age, gender, timing and mode of conflict, Glasgow coma scale (GCS) at arrival, injury spectrum, hospital stay, the modified Rankin score (MRS), mini mental status examination (MMSE), and surgical site infections (SSI).

Results Twenty-eight patients were eligible for analysis. The mean age of presentation was $40.67 \pm 13.99$ years. There were 23 males (82.15\%). Most common time of attack was during dawn $(n=11,39.28 \%)$ followed by dusk $(n=9,32.14 \%)$ and day $(n=8,28.57 \%$ ) time. Provoked conflicts were seen in $64.28 \%$. The mean preoperative GCS was $11.07 \pm 3.54$ and hospital stay was $18.71 \pm 9.51$ days. Skull fractures were

Keywords

- bear maul

- traumatic brain injury

$-\mathrm{TBI}$

- man versus wild

- head injury found in $24 / 28(85.71 \%)$. The mean MRS was $1.67 \pm 1.38$ at a mean follow-up of 14.53 \pm 6.59 months. Favorable outcome (MRS $\leq 2$ ) was seen in $64.28 \%$ of patients. The mean MMSE score was $22.28 \pm 5.36$. Eight patients developed SSI (28.57\%).

Conclusion Outcomes of TBI due to bear maul depend on preoperative GCS. There are higher incidences of skull fractures and SSI. Humans need to avoid infiltration in wildlife territory to reduce the number of conflicts.
\end{abstract}

\section{Introduction}

With the increasing population, humans are encroaching forests for habitat. While most neurosurgeons are practicing in urban areas, few are in the vicinity of tribal areas and forests. They commonly face devastating cranial and maxillofacial injuries arising due to conflicts of man versus wild. Unfortunately, these conflicts occur in the remote areas which barely have any neurosurgical and maxillofacial facilities, and survival primarily depends on the severity of the injuries and timely reach to the tertiary care center at Raipur. published online June 10, 2021
DOI https://doi.org/

$10.1055 / \mathrm{s}-0041-1727580$

ISSN 0976-3147 (c) 2021. Association for Helping Neurosurgical Sick People.

This is an open access article published by Thieme under the terms of the Creative Commons Attribution-NonDerivative-NonCommercial-License, permitting copying and reproduction so long as the original work is given appropriate credit. Contents may not be used for commercial purposes, or adapted, remixed, transformed or built upon. (https://creativecommons.org/licenses/by-nc-nd/4.0/).

Thieme Medical and Scientific Publishers Pvt. Ltd. A-12, 2nd Floor, Sector 2, Noida-201301 UP, India 
The Chhattisgarh state is blessed with a forest area of approximately $59,772 \mathrm{~km}^{2}$, covering $44.21 \%$ of the state's geographical area, and ranks third in the country in terms of forest covers. The state is god gifted with multiple mineral resources, tropical dry deciduous forests, and wildlife sanctuaries. The livelihood of nearly 7 million tribal populations depends on these forests that contribute to nearly 2,000 crores of annual revenue to the state. Approximately $50 \%$ of the villages lie within a $5-\mathrm{km}$ radius of the forest. ${ }^{1}$ Humans have not left any demarcation line between wild animals and them in a quest for livelihood. At times, animals also encroach for food that leads to a conflict between man versus wild, resulting in undesirable situations compromising the life of both.

The available literature is mainly focused only on bears, attacks pattern, and methods of prevention. Maximum studies from India are reported from Kashmir valley, the home of the Asiatic black bear (Ursus thibetanus), and primarily focus on maxillofacial injury management, but data about the management of the neurological injury is scarce. ${ }^{2-5}$ This study intends to highlight and describe the management challenges and outcomes of traumatic brain injury (TBI).

\section{Materials and Methods}

We conducted a retrospective analysis of all the TBI cases due to bear mauling from May 2018 to April 2020 (24 months). Clinical data were collected from the medical records, and the data about circumstances leading to such conflicts were recorded at the last follow-up. The patients who were only having maxillofacial or other injuries without any clinical or radiological evidence of TBI (TBI) were excluded from the study. The last clinical follow-up was recorded till November 2020, and consent was taken for inclusion in the study. Clinical photographs were collected from the departmental library. The variables studied were age, gender, timing of conflict, mode of conflict, Glasgow coma scale (GCS) at arrival, computed tomography $(\mathrm{CT})$ findings and injury spectrum, hospital stay, surgical site infections (SSI), status of wound healing, and duration of follow-up. Neurological outcomes were assessed with the modified Rankin scale (MRS), ranging from 0 to 6 . While a 0 score represents no symptoms at all, a score of 6 represents dead. MRS is a commonly used scale to measure the degree of disability or dependence. The cognitive functions were evaluated with the mini mental status examination (MMSE) which is a simple cognitive assessment test and scores range from 0 to 30 . A score of $\geq 24$ suggests normal cognitive function, 19 to 23 suggests mild dysfunction, 10 to 18 suggests moderate dysfunction, and a score of $\leq 9$ indicates severe dysfunction. The literature review was conducted with keywords like "bear maul," "bear bite," and "bear injury" across the database of PubMed, Scopus, Medline/Medscape, and Cross Reference.

Statistical analysis was performed using statistical packages for SPSS 25.0 for Windows (SPSS Inc., Chicago, Illinois, United States). Univariate descriptive analysis was done for all variables. Continuous and categorical variables were expressed as mean \pm SD. The $t$-test and analysis of variance (ANOVA) test with post hoc analysis were used to compare means. Two-tailed $p$-values were considered statistically significant at $p<0.05$.

\section{Results}

There were a total of 79 patients admitted with such incidence during the study period. Fifty-one patients were excluded due to the absence of any clinical or radiological evidence of TBI. A total of 28 patients were included in the final analysis ( - Fig. 1). The mean age of presentation was $40.67 \pm 13.99$ years (range: $10-75$ years). There were 23 males $(82.15 \%)$ and 5 females (17.85\%). Most common time of attack was during dawn $(n=11$, $39.28 \%$ ) followed by dusk $(n=9,32.14 \%)$ and day $(n=8,28.57 \%)$ times. Nearly two-thirds of attacks $(18 / 28,64.28 \%)$ were due to animal provokes ( $\mathbf{- T a b l e ~} \mathbf{1}$ ).

The mean preoperative GCS at presentation was $11.07 \pm 3.54$ (range: 5-15). Based on the GCS score, patients were grouped in mild head injury ( $n=10 / 28,35.71 \%$ ), moderate head injury ( $n=11 / 28,39.28 \%$ ), and severe head injury $(n=7 / 28,25 \%)$ categories. Mean age was not significantly different among groups. Skull fractures were found in 24/28 (85.71\%), out of which 16 (66.6\%) were of the depressed type, five (20.83\%) were of linear type, two had anterior skull base fracture with CSF rhinorrhea, and one patient had coronal suture diastasis. Frontal bone was most commonly fractured (15/28, 53.57\%), followed by parietal bone in eight and temporal bone in three patients. No fracture was seen in the occipital bone ( - Table $\mathbf{1}$ ). A total of $22 / 28$ patients required surgical intervention for TBI, while six patients required only scalp repair without any cranial intervention. Clinical and radiological photographs of selected patients are shown in -Figs. 2 and 3, respectively. A total of 16 out of $28(57.14 \%)$ patients required plastic and maxillofacial procedures in addition to the cranial procedures. A total of five patients (17.85\%) required tracheostomy.

The mean MRS was $1.67 \pm 1.38$ (range: $0-4$ ) at the mean follow-up of $14.53 \pm 6.59$ months (range: $6-30$ months). The mean MRS was dependent on GCS at the time of presentation, and patients with mild head injury had significantly better mean MRS score than moderate and severe head injuries $(p<0.05)$. Likewise, the moderate head injury group had a significantly better mean MRS score than the severe head injury group. Altogether favorable outcome (MRS $\leq 2$ ) was seen in 18 (64.28\%) patients (-Tables 2 and 3). There was no death in the cohort. A total of six patients (21.42\%) had permanent neurological deficits.

The mean MMSE score was $22.28 \pm 5.36$ (range: 10-29). While the mean MMSE among mild and moderate head injury groups was not statistically different $(p=0.43)$, the mean MMSE score was significantly lower in the severe head injury group $(p<0.05)$. A total of 16 patients $(57.14 \%)$ had normal cognitive function (MMSE score $\geq 24$ ), while there were 6 patients (21.42\%) each in mild(MMSE score 19-23) and moderate(MMSE score 10-18) cognitive dysfunction groups (- Tables 2 and $\mathbf{3}$ ).

A total of eight patients developed SSIs (8/28, 28.57\%; -Fig. 4). The primary organism isolated were Staphylococcus aureus in five, Escherichia coli in two, Pseudomonas in one, and multiple isolates in three patients. Scalp wound was healed by 


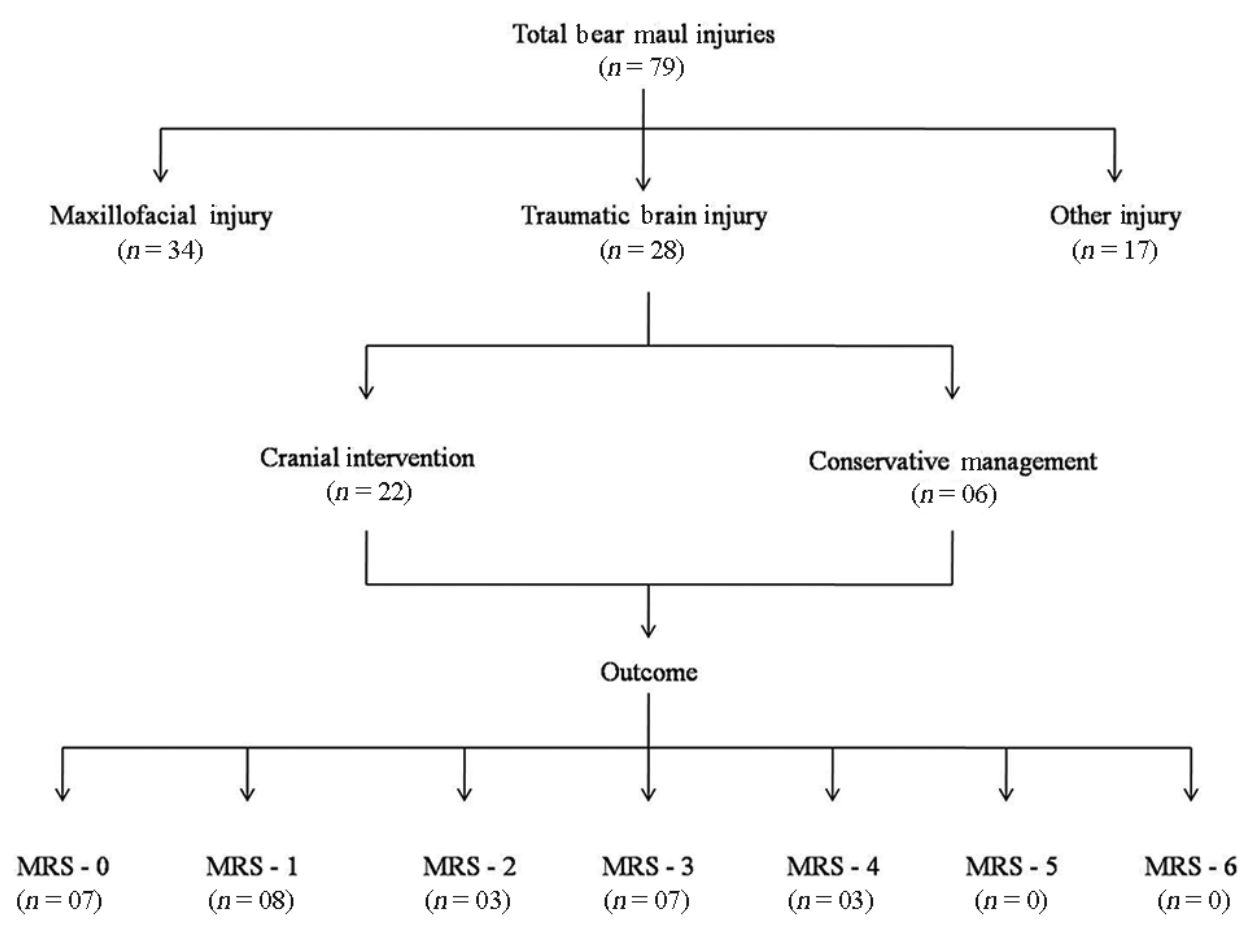

Fig. 1 Pictorial representation of brake-up of all bear maul injuries, management, and neurological outcomes. Other injuries includes limb and torso injuries. MRS, the modified Rankin scale.

Table 1 Patient's demographic details and spectrum of traumatic brain injury

\begin{tabular}{|c|c|}
\hline Variables & $n(\%)$ \\
\hline $\mathrm{M} / \mathrm{F}$ & $23: 5(82.14: 17.85)$ \\
\hline Provoked/unprovoked attacks & $18: 10(64.28: 35.71)$ \\
\hline \multicolumn{2}{|l|}{ Time of attack } \\
\hline Dusk & 09 (32.14) \\
\hline Dawn & $11(39.28)$ \\
\hline Day & $08(28.75)$ \\
\hline \multicolumn{2}{|l|}{ Head injury severity } \\
\hline Mild & $10(35.71)$ \\
\hline Moderate & $11(39.28)$ \\
\hline Severe & $07(25)$ \\
\hline \multicolumn{2}{|l|}{ Cranial injury } \\
\hline Skull fractures & $24(85.71)$ \\
\hline Depressed type & $16(66.67)$ \\
\hline Linear type & $05(20.83)$ \\
\hline Skull base & $02(8.33)$ \\
\hline Suture diastasis & $01(4.16)$ \\
\hline Cerebral contusions & $19(67.85)$ \\
\hline Acute SDH & $05(20.83)$ \\
\hline EDH & $04(14.28)$ \\
\hline CSF rhinorrhea & $02(8.33)$ \\
\hline Eye ball injury & $04(14.83)$ \\
\hline SAH & $07(25)$ \\
\hline DAI & $01(3.57)$ \\
\hline IVH & $02(8.33)$ \\
\hline
\end{tabular}

Abbreviations: CSF, cerebrospinal fluid; DAl, diffuse axonal injury; EDH, extra-dural hemorrhage; $\mathrm{F}$, female; IVH, intraventricular hemorrhage; $\mathrm{M}$, male; SAH, sub-arachnoid hemorrhage; SDH, sub-dural hemorrhage. primary intention in $20 / 28$ (71.42\%), while in eight (28.57\%), healed by secondary intention. One patient developed a cerebral abscess managed conservatively by intravenous (IV) antibiotics.

The mean hospital stay was $18.71 \pm 9.51$ days (range: 8-39 days). The mean hospital stay was significantly higher in the severe head injury group $(p<0.05)$; however, it was not different among mild and moderate head injury groups $(p=0.58)$. The readmission rate was $50 \%(14 / 28)$. Ten patients underwent cranioplasty at an average interval of 3.8 months (range: 1-8 months). Three patients were readmitted for SSIs; of them, two required removal of the bone flap. One patient was readmitted for ventriculoperitoneal (VP) shunt.

\section{Discussion}

\section{Problem Statement}

Of nearly 10,000 sloth bears (Melursus ursinus) in India, nearly 3,000 lives in dens of Chhattisgarh, the largest in India. ${ }^{6}$ This species is included in Schedule I of the Indian Wildlife (Protection) Act 1972 and International Union of Conservation of Nature (IUCN 2010). This forest land is in patches, interspersed with agricultural land with human habitat. The sloth bears live in a den during cold weather and come out during summer and early springs during dusk and dawn (crepuscular) for food collection. Sloth bears mostly feed on ants, termites, honey, and fruits. Secondarily bears are known to raid crops in agricultural farms. In Chhattisgarh, when the temperature rises above $40^{\circ} \mathrm{C}$ during summers, fields are mostly devoid of crops, and most tribal occupants invade forests for fruits and their livelihood on 


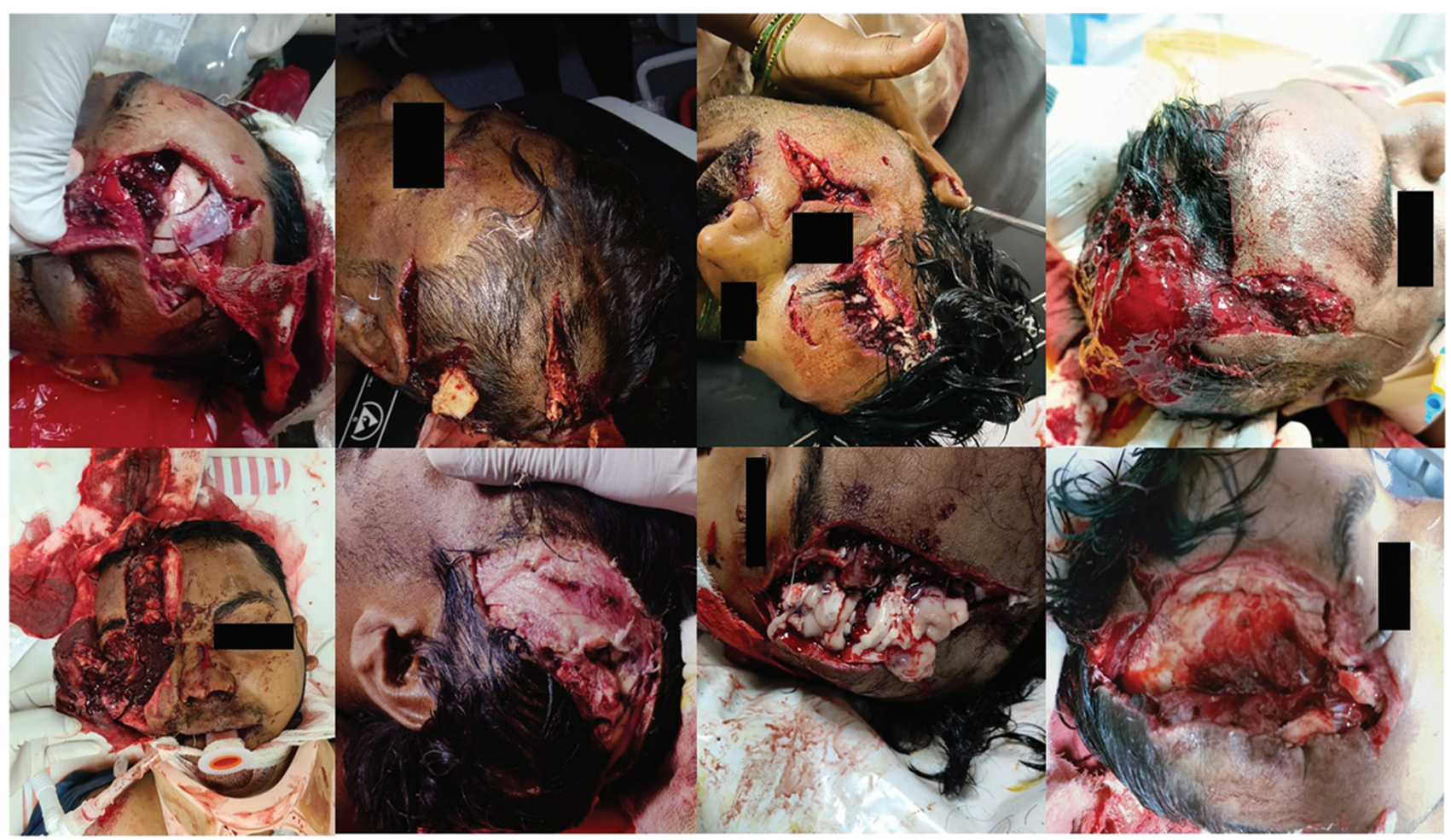

Fig. 2 Clinical photographs of patients showing the extent of tissue damage.

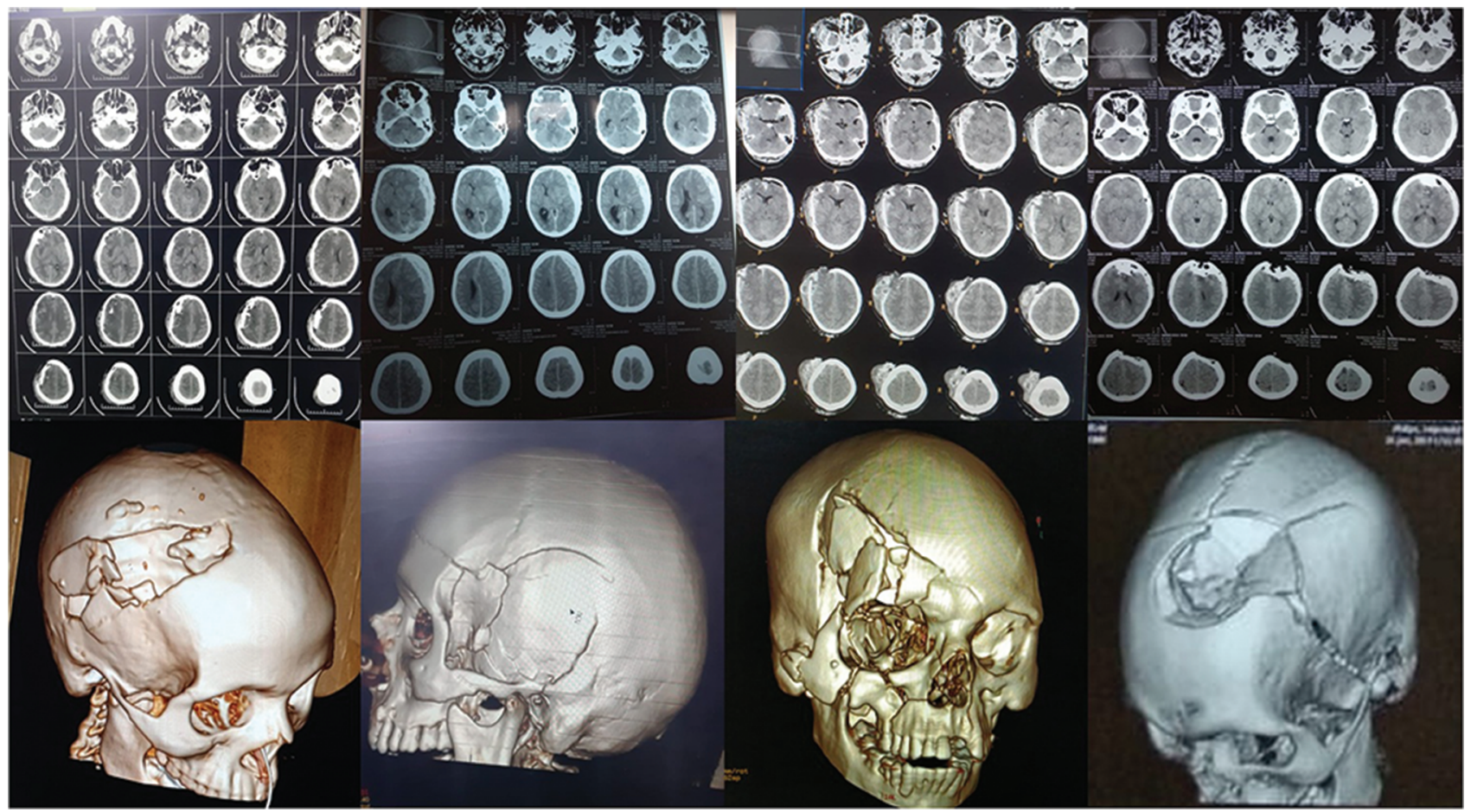

Fig. 3 Radiological evaluation with noncontrast CT and 3D CT demonstrating the extent of traumatic brain injury. 3D, three-dimensional; CT, computed tomography.

rubber plants and tendu leaves. Additionally, tribal populations routinely encroaches forests during dusk and dawn due to a lack of proper sanitation facilities explaining the reasons for most of the conflicts during these hours of the day. This encroach creates competition and conflicts with sloth bears.
The incidence of bear mauling is on the rise in Chhattisgarh. There were 157 such incidents during 2018 to 2019 with a $35 \%$ rise to 202 incidents in the year 2019 to $2020 .{ }^{1}$ In a study published by Bargali et al in 2005, there were 137 such incidents with the loss of 11 humans, and two beer lives in 
32 months in only one forest division. ${ }^{7}$ As per media reports, 215 human had lost their lives due to animal mauling from 2005 to $2014 .^{6}$

\section{The Conflict: Man versus Wild}

According to Rajpurohit and Krausman the sloth bear is one of the most dangerous wild animals. ${ }^{8}$ They are even known for unprovoked attacks. ${ }^{9}$ In the present series, $25 \%$ of the attacks were unprovoked. Their attacks on humans are responsible for $67 \%$ of all animal attacks, with death to injury ratio of 1:14.3. ${ }^{8}$ Average sloth bears can grow up to 6 feet, gain $140 \mathrm{~kg}$ weight, run up to $48 \mathrm{~km} / \mathrm{h}$, and have strong jaws and teeth along with long and sharp nails. ${ }^{5}$ The human body's limits cannot overpower them by any means. The brutal force by bears can shatter any skull, and the pattern of craniofacial injuries is unmatchable and devastating. The conflicts usually occur when neither of both aware of proximity and sudden appearance leads to a panic situation. The bears do so in an attempt to protect their cub, food, or territory. Humans are only left with options like a fight, run, or climb the tree; unfortunately, all are in bears' domains. The only

Table 2 Neurological outcomes of traumatic brain injury due to bear maul

\begin{tabular}{|l|l|}
\hline Outcome variables & $\boldsymbol{n}(\%)$ \\
\hline MRS & $\begin{array}{l}\text { Mean: 1.67 } \pm 1.38 \\
\text { (range: } 0-4)\end{array}$ \\
\hline 0 & $07(25)$ \\
\hline 1 & $08(28.57)$ \\
\hline 2 & $03(10.71)$ \\
\hline 3 & $07(25 \%)$ \\
\hline 4 & $03(10.71)$ \\
\hline Cognitive dysfunction-MMSE score & $\begin{array}{l}\text { Mean: 22.28 } \pm 5.36 \\
\text { (range: 10-29) }\end{array}$ \\
\hline Normal (MMSE $\geq 24)$ & $16(57.14$ \\
\hline $\begin{array}{l}\text { Mild cognitive dysfunction } \\
\text { (MMSE: } 19-23)\end{array}$ & $06(21.42)$ \\
\hline $\begin{array}{l}\text { Moderate cognitive dysfunc- } \\
\text { tion (MMSE: 10-18) }\end{array}$ & $06(21.42)$ \\
\hline $\begin{array}{l}\text { Severe cognitive dysfunction } \\
\text { (MMSE } \leq \text { 9) }\end{array}$ & Nil \\
\hline
\end{tabular}

Abbreviations: MRS, modified Rankin score; MMSE, mini mental status examination.

Note: Favorable MRS (0-2), 18/28, 64.28\%, favorable MMSE (normal and mild cognitive dysfunction): $78.57 \%$. chances of survival are left on mercy by the bear, severity of the injury, and timely reach to the proper medical facility.

Like the present series, mostly males had been found victims in all series. The middle age group ( $30-50$ years) is most commonly affected due to increased outdoor activities. Bargali et al stated most encounters during dusk and dawn but some have reported during the daytime. ${ }^{7}$ In the present series, a total of $75 \%$ of encounters was during dawn and dusk due to human encroachment in forests for sanitation. Rasool et al and Shah et al found most attacks sudden and unprovoked, unlike the present series. ${ }^{2.5}$ We believe that most animals have possessive behavior and only offend when compromised for the safety of themselves and cubs, food, or territory. To restrict bears to the forest territory by providing food and water opportunities, the Chhattisgarh government has started the "Jamvant" Project. The state government also bears the burden to provide compensation aid to the victims. ${ }^{6}$

\section{Spectrum and Mechanism of Injuries}

The first reported surgical management of such injuries dates back to 1891 by Moir. ${ }^{10}$ The data of structures injured varies among reports, but many had found face as a primary target. In a quest to incapacitate their victims and overcome counter attack, bear targets on craniofacial structures which comprise $19 \%$ of injury in one study, while the other published study from Chhattisgarh reported collectively 70\% injury to face and scalp with only two head injury cases. ${ }^{11}$ The injury to the eyeballs makes the victim blind to retaliate. ${ }^{12}$ The brutal force applied by the bear led to multiple shattering of facial bones involving the maxilla, zygoma, mandible, nasal bones, orbit, frontal, and parietal calvarias along with extensive soft tissue injury. ${ }^{5}$ It is common to observe tissue loss to a certain extent. The actual incidence of neurological injury is unknown. Out of a total of 79 patients admitted at our institute, 28 (35.44\%) had a TBI. The actual incidence figures may vary as many victims with minor injuries had not been referred to our center or some would have succumbed either at the scene or in transport. As the frontal region is in direct view of the bear, frontal scalp lacerations, bone fractures, and parenchymal contusions are more common. Temporal, occipital, and skull base were less commonly seen fractured. ${ }^{3,5,13}$ Overall, the spectrum of TBIs matches as of due to road traffic accidents except for higher incidences of skull fractures (especially depressed type) and lower incidences of diffuse axonal injury. Other structures commonly seen

Table 3 Statistical analysis of variables

\begin{tabular}{|l|l|l|l|}
\hline $\begin{array}{l}\text { Head injury } \\
\text { severity }\end{array}$ & $\begin{array}{l}\text { Hospital stay } \\
\text { Mean } \pm \text { SD }(\mathbf{d})\end{array}$ & Mean MRS & Mean MMSE score \\
\hline Mild & $13.90 \pm 8.72$ & $0.3 \pm 0.48$ & $25.70 \pm 1.56$ \\
\hline Moderate & $17.45 \pm 7.86$ & $1.81 \pm 0.87$ & $24.27 \pm 3.19$ \\
\hline Severe & $27.57 \pm 7.56$ & $3.42 \pm 0.53$ & $14.28 \pm 2.69$ \\
\hline Inference & $p(S)$ among categories & $p(S)$ among categories & $\begin{array}{l}p(\text { NS) between mild and moderate category } \\
\text { (S) between mild/moderate and severe category }\end{array}$ \\
\hline
\end{tabular}

Abbreviations: MRS, modified Rankin score; MMSE, mini mental status examination; NS, not significant; S, significant; SD, standard deviation. 


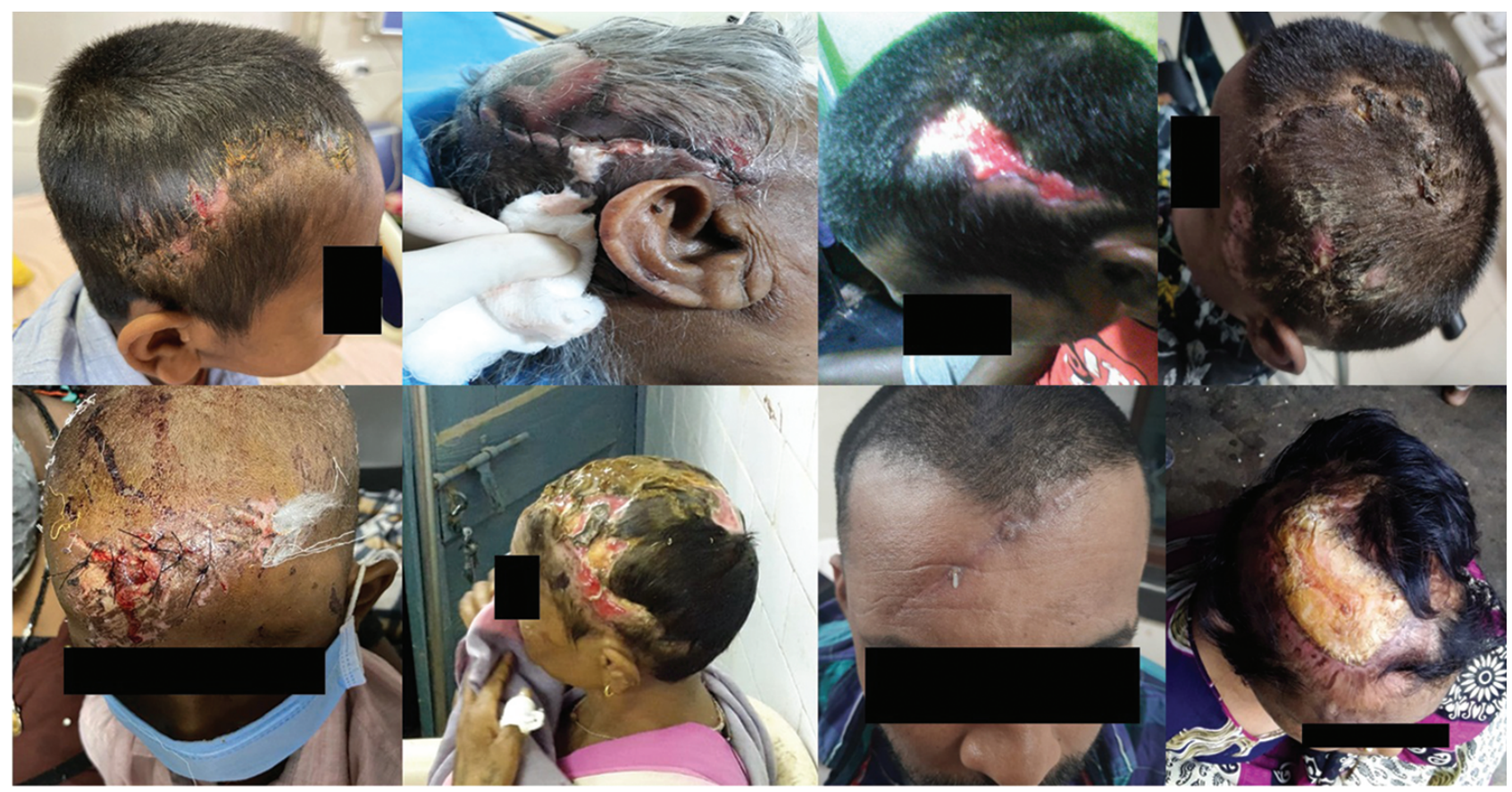

Fig. 4 Clinical photographs of patients who developed surgical site infections.

injured are limbs (55\%) in futile defense attempts. Vascular injuries are also reported in 15 of 212 cases by Wani et al. ${ }^{14}$

\section{Management}

These conflicts occur in remote areas where neurosurgical facilities are still a dream. The majority of these victims were initially taken to the primary health center where the only possible surgical means are first aid. Many of our patients received were wrapped in piles of bandage without primary suturing due to extensive soft tissue damage puzzling the means of repair. All these patients need vitals stabilization, hemostasis, and robust tissue approximation before radiological evaluation.

Another critical issue is airway protection in the setting of severe damage to facial structures leading to inadequate seal and support for mask during bag and mask ventilation. We use cotton mops to provide a seal for slight leak and saline filled surgical gloves to bridge larger gaps. These patients have a high risk of aspiration due to the pooling of blood and saliva in the oropharynx, along with soft tissue damage and edema. ${ }^{15}$ Even the suction and intubation are challenging and may require emergent tracheostomy. Video laryngoscope is a useful aid for assisted intubation. Adequate pain relief is of paramount importance and requires opioid analgesics. Often these patients lose a large pool of blood at the scene and require transfusions. After proper resuscitation, the optimal imaging modality is two-dimensional (2D) and three-dimensional (3D) craniofacial noncontrast CT scan for assessment, planning, and to decide urgency for intervention.

These devastating injuries require a multidisciplinary team approach consisting of neurosurgeons, plastic and maxillofacial surgeons, anesthetists, and intensivists. In an attempt to restore optimal neurological and aesthetic sense, long operative hours fiddling up with leftover devascularized tissue fragments is a necessity. Raising scalp flap for cranial intervention in a customized manner is often not possible, and scalp incisions need to be tailored based on patterns of scalp lacerations and the size of craniotomy required. The main trunk and branches of the superficial temporal artery must be preserved as carefully as possible. These patients require elevation and excision of shattered bone fragments, removal or hematomas, and contusions, and watertight but lax dura repairs from a neurosurgical perspective. We prefer to use either pericranial fascia if possible or fascia lata graft for dura repair instead of artificial substitutes due to infection concerns. We also tend to avoid placing Gelfoam over dura as much as possible. We do not use titanium mesh during the first surgery to cover bony defects due to similar reasons. The scalp is essentially sutured in an interrupted manner rather than continuous. We use prophylactic antiepileptic drugs as a protocol in all cases of parenchymal lacerations.

Aesthetic surgeons have a tough time to find means of tissue approximation after maxillofacial fractures are stabilized with implants. Regions of excess tissue loss segment require rotation or pedicle flap for coverage. In a delayed presentation with infection and devitalized tissue, the only debridement should be considered and primary closure is withheld till the resolution of infection. Some patients require multiple-stage operations due to the complexity of defects. Due to injury to the associated facial nerve, even with good tissue approximation, functional results are suboptimal, ${ }^{16}$ and such disfigured faces retract themselves from social appearances and experience posttraumatic stress disorders, the importance of psychiatric management cannot be undermined. ${ }^{17}$ Mild and moderate cognitive dysfunctions on MMSE were seen in six cases (21.42\%) in each group in the present study. To the best of our knowledge, 
this is the only study which has assessed cognitive dysfunction using MMSE score till date in bear maul injuries.

These wounds are often full of contamination with gram-positive (Streptococcus and mostly Staphylococcus) and gram-negative (E. coli and Enterobacter) organisms. ${ }^{18}$ The other organisms isolated from cultures were Serratia, Enterococcus, Bacillus, Aeromonas, Neisseria, Prevotella, and Propionibacterium. ${ }^{19}$ They need broad-spectrum antibiotics coverage initially and subsequently based on cultures. ${ }^{20}$ Wounds need to be debrided, irrigated copiously with normal saline, hydrogen peroxide, and povidone-iodine to reduce contamination. We practice the local use of chloromycetin irrigation before closure in addition to systemic antibiotics. The SSI rate due to bear maul in the present study is higher than our other TBI cases due to road traffic accidents (28.57\% vs. $11.13 \%$ ). Most of the articles had advocated using penicillin and cephalosporins for broad-spectrum coverage, and Pukar et al found garenoxacin and oral des-fluoroquinolone helpful. ${ }^{21}$ We believe broad-spectrum coverage should include gram-negative and anaerobes as well. Our policy is to start piperacillin or tazobactum and aminoglycosides and metronidazoles at first go and modify once aware of culture and sensitivity.

The use of postexposure tetanus and antirabies prophylaxis is a common practice and is recommended. ${ }^{22}$ Some surgeon even locally infiltrates human rabies immunoglobulin before closure. ${ }^{23}$ In our series, we avoid local infiltrations. We administered both human rabies immunoglobulin (HRIG) and antirabies vaccine on day 0 and repeated administration of antirabies vaccine on day 3,7 , and 14 . Anesthetic drugs, especially ketamine, lessen the effect of the antirabies vaccine. ${ }^{24,25}$ In an ideal case scenario, one should wait for surgery and anesthesia up to 1 week after inactive vaccination and up to 3 weeks after live vaccination. ${ }^{26}$ Due to the emergency nature and concerns about infections, one cannot help instead, operate at the earliest opportunity. None of our patients developed rabies or tetanus in the postoperative period.

The neurological outcome of these patients is generally satisfactory and primarily depends on the severity of the head injury. The favorable outcome (MRS: $0-2$ ) in the present series was seen in nearly two-thirds (64.28\%) of patients, and nearly three-fourths (78.57\%) did fare (normal or mild cognitive dysfunction) on MMSE. From an esthetic perspective, the final impression looks rewarding, and they live with deformity and morbidity. Causes of death at the scene are primarily due to hypotension, aspiration, and cranial and cervical injuries. ${ }^{27}$ In patients who manage to reach the hospital live and stable, the primary cause of death is cranial injuries. ${ }^{3,4,11}$ In the literature review, we only found a single death secondary to septicemia. ${ }^{28}$ There was no life lost in our cohort.

Cranioplasty after decompressive craniectomy in these patients also needs special consideration. We prefer to defer cranioplasty until wound healing is satisfactory without signs of infection, and optimal neurological status is achieved. A total of 10 cranioplasties was performed at an average interval of 3.8 months in the present study. As mentioned previously, scalp flaps of these patients are often tailor made; incising scalp over previous scars and raising flap for cranioplasty need meticulous dissection avoiding injury to underlying brain parenchyma. We prefer to use titanium mesh for cranioplasty.

\section{Conclusion}

The bear maul-induced injuries are on the rise in Chhattisgarh. Being higher in evolution, humans need to respect wild territories and avoid infiltration. Mankind bears the responsibility to protect themselves and wild animals. Humans being slender in body structure can no way retaliate or win the man versus wild battle. In case of such incidents, victims should be transported early after stabilization to a proper facility where a multidisciplinary team is available. There are higher incidences of skull fractures and SSIs in TBI due to bear maul. The outcomes of such injuries primarily depend on the severity of traumatic brain injuries.

\section{Funding}

None.

\section{Conflict of Interest}

None declared.

\section{Acknowledgments}

The authors sincerely thank Dr. Hemant Sharma for the statistical analysis. They are thankful to Mrs. Praveena Mishra, a clinical psychologist, for immense help in evaluating cognitive functions. they are also thankful to Drs. Naman Chandrakar and Shashank Nahar for data collection.

\section{References}

1 Forest and Climate Change Department, Government of Chhattisgarh. Introduction. Accessed February 11, 2021 at http://www.cgforest.com/category/introduction

2 Rasool A, Wani AH, Darzi MA, et al. Incidence and pattern of bear maul injuries in Kashmir. Injury 2010;41(1):116-119

3 Bashir SA, Rasool A, Zaroo MI, et al. Bear maul craniocerebral trauma in Kashmir Valley. J Craniofac Surg 2013;24(1):e2-e5

4 Nabi DG, Tak SR, Kangoo KA, Halwai MA. Increasing incidence of injuries and fatalities inflicted by wild animals in Kashmir. Injury 2009;40(1):87-89

5 Shah AA, Mir BA, Ahmad I, Latoo S, Ali A, Shah BA. Pattern of bear maul maxillofacial injuries in Kashmir. Natl J Maxillofac Surg 2010;1(2):96-101

6 Times of India (TOI). Human-animal conflict on the rise in Chhattisgarh, sloth bear attacks five including minors. Accessed April 2, 2016 at https://timesofindia.indiatimes. $\mathrm{com} /$ city/raipur/Human-animal-conflict-on-the-rise-inChhattisgarh-sloth-bear-attacks-five-including-minors/articleshow/51662657.cms

7 Bargali HS, Akhtar N, Chauhan NPS. Characteristics of sloth bear attacks and human casualties in North Bilaspur Forest Division, Chhattisgarh, India. Ursus 2005;16(2):263-267

8 Rajpurohit KS, Krausman PR. Human sloth bear conflicts in Madhya Pradesh, India. Wildl Soc Bull 2000;28(2):393-399

9 Ghezta NK, Bhardwaj Y, Ram R, Ahsan R, Arya S. Incidence pattern of bear-inflicted injuries to the maxillofacial region-soft and hard tissue injuries, their management, and sequelae. J Oral Maxillofac Surg 2019;77(5):1043.e1-1043.e15 
10 Moir DM. Plastic operation on face for bite from a bear. Ind Med Gaz 1891;26(3):74-76

11 Siddharth RK, Kujur SP, Shivhare PR, Gulhane PV, Arya RC. Study of bear bite injury and management in tribal belt of Chhattisgarh, India. J Evid Based Med Healthcare 2020;7(1):34-37

12 Roka YB, Roka N, Shrestha M, Puri PR, Adhikari HB. Penetrating head injury with bilateral eye avulsion due to Himalayan bear bite. Emerg Med Australas 2012;24(6):677-679

13 Prasad SC, Thada ND, Rao P, Thada SR, Prasad KC. Grievous temporal and occipital injury caused by a bear attack. Case Rep Otolaryngol 2013;2013:957251

14 Wani ML, Ahangar AG, Lone GN, et al. Vascular injuries after bear attacks: Incidence, surgical challenges and outcome. J Emerg Trauma Shock 2011;4(1):20-22

15 Naitam J, Mamtani P. Anaesthesia challenges in patients with bear bite. Int J Biomed Res 2017;8(12):694-698

16 Lone PA, Kouser T, Iqbal A. Unusual bear maul injuries. J Dent Res Development 2015;5(1):11-22

17 Ram R. Maxillofacial injuries due to bear mauling. J Maxillofac Oral Surg 2011;10(1):85-89

18 Kunimoto D, Rennie R, Citron DM, Goldstein EJC. Bacteriology of a bear bite wound to a human: case report. J Clin Microbiol 2004;42(7):3374-3376

19 Thomas N, Brook I. Animal bite-associated infections: microbiology and treatment. Expert Rev Anti Infect Ther $2011 ; 9(2): 215-226$
20 Floyd T. Bear-inflicted human injury and fatality. Wilderness Environ Med 1999;10(2):75-87

21 Pukar M, Hajare A, Krishnaprasad K, Bhargava A. Garenoxacin in skin \& skin structure infections complicated by bear bite. Int J Med Res Health Sci 2014;3(2):503-505

22 Manning SE, Rupprecht CE, Fishbein D, et al; Advisory Committee on Immunization Practices Centers for Disease Control and Prevention (CDC). Human rabies preventionUnited States, 2008: recommendations of the Advisory Committee on Immunization Practices. MMWR Recomm Rep 2008;57(RR-3) :1-28

23 Vashistha A, Singh M, Kaur G, Gupta S. Bear maul injury in maxillofacial region: a case report. Traumaxilla 2019;1(1):22-25

24 Fescharek R, Franke V, Samuel MR. Do anaesthetics and surgical stress increase the risk of post-exposure rabies treatment failure? Vaccine 1994;12(1):12-13

25 Crowcroft NS, Elliman D. Vaccination and anesthesia: the precautionary principle is to vaccinate. Paediatr Anaesth 2007;17(12):1216-1218, author reply 1218-1220

26 Short JA, van der Walt JH, Zoanetti DC. Immunization and anesthesia - an international survey. Paediatr Anaesth 2006;16(5):514-522

27 Tough SC, Butt JC. A review of fatal bear maulings in Alberta, Canada. Am J Forensic Med Pathol 1993;14(1):22-27

28 Phalke B, Waghmare S, Zine KU. Bear bite: a case report. J Forensic MedSci Law 2014;23(2):1-5 